\title{
Successful use of flecainide to treat new onset maternal ventricular tachycardia in pregnancy
}

\author{
Mark Connaughton, B Stephen Jenkins
}

Cardiac Department, St Thomas' Hospital, London

M Connaughton

B S Jenkins

Correspondence to:

Dr M Connaughton,

Cardiac Department, St

Palace Road, London SE1 7EH
Thomas' Hospital, Lambeth

\begin{abstract}
A 37 year old West Indian woman presented at 31 weeks' gestation after six recent syncopal episodes. Apart from mild gestational diabetes her pregnancy had been unremarkable. The syncopal episodes usually followed irregular palpitation. Examination showed a basically regular pulse with frequent extrasystoles, no clinical ventricular hypertrophy or heart failure, and a blood pressure of 105/60 mm Hg. A pansystolic murmur radiated widely. The fetus appeared healthy.

Urea, electrolytes, glucose, and thyroid function were normal. A mild anaemia and blood film were consistent with known sickle cell trait. A resting 12 lead cardiogram showed frequent ventricular extrasystoles but no evidence of ventricular preexcitation and a normal QT interval. A $48 \mathrm{~h}$ electrocardiogram showed frequent episodes of polymorphic sustained broad complex tachycardia (figure). Transthoracic echocardiography showed normal right and left ventricular function, normal cardiac dimensions, and minimal mitral regurgitation.

Inpatient treatment with oral flecainide (100 mg twice a day) gave good relief of her palpitation and fewer episodes of tachycardia.
\end{abstract}
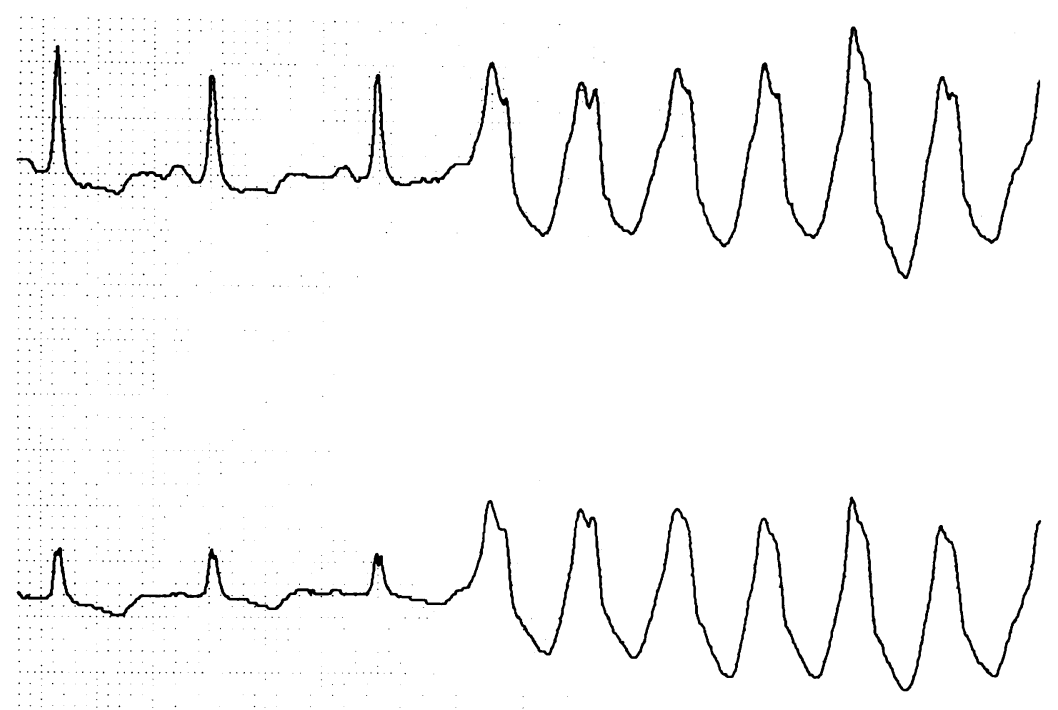

Extract from a two channel 48 h electrocardiogram showing three sinus beats followed by a run of broad complex tachycardia at a rate of $180 /$ minute. Scale bar $=1$ second.
A further $24 \mathrm{~h}$ electrocardiogram showed virtual resolution of her tachyarrhythmia. The remainder of the pregnancy was uneventful and she was delivered of a live boy at term by caesarean section. Flecainide was stopped 18 days after delivery. A subsequent $24 \mathrm{~h}$ electrocardiogram was normal.

New onset maternal ventricular tachyarrhythmias are rare in pregnancy, with fewer than 30 cases reported. There is no known association with structural heart disease and the overall outlook is generally good for both mother and fetus. ${ }^{1}$ The cause of our patient's tachycardia remains unclear. Maternal arrhythmias may be catecholamine sensitive as determined by a raised basal heart rate, inducibility by exercise, and suppression by sleep. Our patient showed raised resting heart rate and partial suppression of the tachyarrhythmia during sleep. This was consistent with a catecholamine sensitive aetiology.

Perhaps because of such reasoning, $\beta$ adrenergic blockers have been favoured in North America for first-line treatment of maternal ventricular arrhythmias. ${ }^{1}$ Our obstetricians were concerned about the effects of $\beta$ blockers on umbilical blood flow and the risk of triggering of premature labour. We did not use amiodarone because it might have caused fetal thyroid dysfunction. ${ }^{2}$ Flecainide has little known fetal toxicity, has been used to treat fetal tachycardias, ${ }^{3}$ and was thought likely to achieve early suppression of the tachycardia.

We suggest that flecainide should be regarded as an effective agent in terminating and suppressing maternal ventricular tachycardia in pregnancy, particularly if there are contraindications to $\beta$ blockade.

1 Brodsky M, Doria R, Allen B, Sato D, Thomas G, Sada M. New-onset ventricular tachycardia in pregnancy. $\mathrm{Am}$ Heart $₹$ 1992;123:933-41.

2 Matsumura LK, Born D, Kunii IS, Franco DB, Maciel RM. Outcome of thyroid function in newborns from mothers treated with amiodarone. Thyroid mothers trea

3 Allan LD, Chita SK, Sharland GK, Maxwell D, Priestley $\mathrm{K}$. Flecainide in the treatment of fetal tachycardias. $\mathrm{Br}$ Heart $₹$ 1991;65:46-8. 